Research Report

553

\title{
MODULUS AND DAMPING OF ASPHALTIC CONCRETE USING THE RESONANT COLUMN
}

\author{
by \\ David L. Allen \\ Research Engineer Chief
}

and

Robert C. Deen

Assistant Director

\author{
Division of Research \\ Bureau of Highways \\ DEPARTMENT OF TRANSPORTATION \\ Commonwealth of Kentucky
}

\footnotetext{
offered for publication by

The American society for

Testing and Materials
}

September 1980 


\section{INTRODUCTION}

When analyzing flexible pavements or predicting their behavior by such means as elastic-layered theory or by finite elements, it is necessary to know the farameters that govern the behavior of the ravement components. One of the most important factors to consider is the modulus of the asphalt bound layers.

In the past two decades, one method that has seen increasing use in the determination of the moduli of engineering materials (particularly soils) is the resonant column. However, its use in determining the moduli of asphaltic concrete has not been widespread or well documented. In this study, which was part of a larger study on pavement rutting (1), attempts have been made to adapt the resonant column to testing asphaltic concrete. $A$ brief summary of resonant column theory and a discussion of equipment, problems, and results are presented.

\section{EQUIPMENT}

The equipment used in this study was the Drnevich Longitudinal-Torsional Resonant Column, designed by V. P. Drnevich of the University of Kentucky. Figure $I$ is a photographs showing the basic unit, without the supporting electronics. To vibrate the specimen either longitudinally or torsionally, a sinusoidal (AC) current is sent through the single longitudinal coil or four torsional coils, respectively, thus sending a longitudinal or torsional wave through the specimen.

Figure 2 is a schematic diagram of the supporting electronic equipment. The sinusoidal excitation is generated by a variable oscillator, amplified to drive the electromagnets which vibrate the column. Specimen response is monitored by two accelerometers (one each for longitudinal and torsional motions) mounted on the top platen. Output from the power amplifier (driving force) and output from the accelerometers are monitored on a dual beam oscilloscope. The resulting patterns are defined as Lissajous' figures. Lissajous' figures represent the vector sum of two sine waves (the driving force and the induced acceleration). During a test, as the oscillator is advanced through a range of frequencies, the figure grows in size, and the major and minor axes of the elipse align themselves with the horizontal and vertical axes of the screen. When this occurs, the acceleration of the vibrating assembly (including the test specimen) is $90^{\circ}$ out of phase with the driving force. This occurs at the undamped natural frequency of the test specimen. This frequency is used to obtain the specimen modulus.

To test the specimens through a range of temperatures, a copper heating coil was installed on the aluminum base plate. A 50-percent alcohol-water solution was circulated through the coil and back to a constant temperature water bath. Temperatures were monitored with a thermometer meeting ASTM Standard E 1 (Thermometer No. 31F) mounted on the test specimen. 
The farticular model of the Drnevich Resonant Column used in this study was designed frimarily for soil testing. The vibrating top mass for this unit had a bottom and top plate that were partially free to vibrate, and an aluminum base plate that was supported on three legs (see Figure 1). When the machine was calibrated, the resonant frequency of the system appeared to be approximately $900 \mathrm{~Hz}$. It was suspected that most of the vibration at that frequency was coming from the two items just mentioned.

It was estimated, however, that the asphaltic specimens would have resonant frequencies well above $900 \mathrm{~Hz}$. Therefore, the Drnevich Resonant Column was modified considerably. The aluminum base plate and its three supporting legs were replaced by a base plate of solid steel. The vibrating top mass was radically redesigned from a "hollow" rectangular unit composed largely of aluminum with attached torsional maynets to a circular unit of solid stainless-steel without torsional capabilities. This greatly reduced internal vibrations and increased system resonance to well over $2,000 \mathrm{~Hz}$. Figure 3 is a photograph showing the modified equipment.

\section{MATERIALS AND METHODOLOGY}

The asphaltic concrete mixture used in this study contained crushed limestone aggregate and was graded as shown in Figure 4. It contained E.2 percent of an AC.20 asphalt cement. Specimens were compacted in a split mold having a double plunger (top and bottom). The material was reheated to $300^{\circ} \mathrm{F}\left(149^{\circ} \mathrm{C}\right)$, and the proper quantity of material was weighed into a heated mold. The materials were compressed under a 5,000-pound $(22.24-\mathrm{kN})$ static load for 2.5 minutes. The average temperature at the time of compaction was $280^{\circ} \mathrm{F}\left(138^{\circ} \mathrm{C}\right)$. The average height was 3.0 inches $(76 \mathrm{~mm})$ and the average diameter was 2.0 inches $(51 \mathrm{~mm})$. The specimen densities were 138 pounds per cubic foot $(2,247$ $\mathrm{kg} / \mathrm{m}^{3}$ ), which is 90 percent of the Marshall density.

After compaction, the specimens were capped with a high-modulus, sulfur-base capping compound to insure smooth uniform ends. The specimens were then glued in place with epoxy. In the latter phases of this study, the surface of the sample pedestal and the sample top platen were knurled. The hot capping compound was poured on these surfaces and the specimens was fixed in place while the material was still hot, thus eliminating the glue.

After the sample was in place, the heating coil was installed along with magnet supports and the driving coils. The lucite chamber and chamber top were assembled and the chamber was filled with glycerin. Glycerin was used as the chamber fluid because water produced a large amount of condensation inside the chamber at the higher test temperature. The specimens remained in the chamber at the chosen temperature for 24 hours before testing. The undamped natural frequency was then obtained as described in the section on equipment. 


\section{TESTING PROBLEMS}

When testing stiff specimens with high resonant frequencies, it is sometimes difficult to determine true resonance of the specimen. A number cf small harmonics will usually appear as the oscillator is tuned through higher frequencies (greater than 1,000 Hz). For this reason, great care and judgment must be exercised in choosing specimen resonance. Also, if one of these harmonics occurs close to specimen resonance, the results can be seriously affected because spurious machine vibrations are probably being detected.

Coupling is very important in resonant column testing (2). If firm contact is not made and maintained between the specimen ends and their adjacent machine parts, the results will be unreliable. In the early phases of this study, an epoxy glue was used to provide coupling; however, Young's modulus of the glue was less than the modulus of some of the specimens. This resulted in incorrect moduli readings and was, therefore, abandoned. As discussed previously, a sulfur-based capping corpound was used instead of the glue. This provided better longitudinal coupling: however, there were still coupling problems in the torsional mode. It is for this reason that only the longitudinal test results are discussed in this paper.

\section{RESULTS}

The average moduli for three specimens run at three different temperatures are shown in Figure 5. These values are compared to values of the complex elastic modulus, $E^{*}$, reported by Kallas and Riley (3), which were obtained from pavement cores of asphaltic concrete base having a comparable density. The two curves in Figure 5 are very different, with the resonant column curve exhibiting an apparently "flatter" response. There is, however, some concern about the reliability of the data point at $37^{\circ} \mathrm{F}\left(3^{\circ} \mathrm{C}\right)$. When analyz. ing the frequency and amplitude response of the coldest specimens at what appeared to be resonance, it was apparent the accelerometer was reporting spurious vibrations that were being superimposed on the specimen response. Further analysis seemed to implicate various parts of the apparatus itself as the source of these unwanted vibrations. It is not certain, but this may have caused the modulus to appear lower than expected.

Because of the extremely low values of strain, it was expected that values of modulus from the resonant column would be somewhat higher than the $r$.oduli calculated from the more conventional methods of dynamic testing. This appeared to hold true for the values of modulus at the two highest test temperatures.

Figure 6 illustrates the effects of temperature and force magnitude on strain amplitude. The relationship was as expected; higher temperatures and larger forces produced larger strain amplitudes. Strain amplitudes from the resonant column are often in the range of 100 times less than strain amplitudes from conventional dynamic tests. Force magnitudes are 
generally expressed in terms of millivolts (see Figure 6) instead of conventional force units because total force on the test specimen is always very small (less than 1 pound $(4.45 \mathrm{~N}$ ) in this study).

Figure 7 shows that temperature was also an important factor in the magnitude of damping. Damping ranged from 9.4 percent at $97^{\circ} \mathrm{F}\left(36^{\circ} \mathrm{C}\right)$ to 1.8 percent at $37^{\circ} \mathrm{F}\left(3^{\circ} \mathrm{C}\right)$. Within the range of forces used in this study, damping did not appear to be affected by the magnitude of applied force. As indicated in Figure 7, the values of damping remained well below 25 percent; therefore, the theoretical assumptions of elasticity appear not to have been violated.

\section{CONCLUSIONS}

1. Although not completely supported by the data, it may be that values of the modulus for test specimens at temperatures below $50^{\circ}$ or $60^{\circ} \mathrm{F}\left(10^{\circ}\right.$ or $\left.16^{\circ} \mathrm{C}\right)$ for this particular study would be somewhat unreliable.

2. As expected, the percentaye of damping increases as the temperature increases.

3. Strain amplitude increases as the maynitude of force and temperature increases.

4. The two most troublesome problems in this study of very stiff specimens were possible spurious machine vibrations that are detected in the higher frequency ranges and difficulty in maintaining good coupling between the specimen and adjacent machine parts.

\section{REFERENCES}

1. Allen, D. L.; Determination of Rutting in Asphaltic Concrete Pavements; Field Instrumentation and Laboratory Characterizations, Division of Research, Kentucky Bureau of Highways, Lexington, Kentucky, August 1978.

2. Drnevich, V. P., Resonant-Column Testing .. Problems and Solutions, Dynamic Geotechnical Testing, Standard Technical Publication 654, American Society for Testing and Materials, Philadelphia, Pennsylvania, 1978.

3. Kallas, B. F., and Riley, J. C.; Mechanical Properties of Asphalt Pavement Materials, Proceedings, Second International Conference on Structural Design of Asphalt Pavements, The University of Michigan, Ann Arbor, Michigan, 1967. 


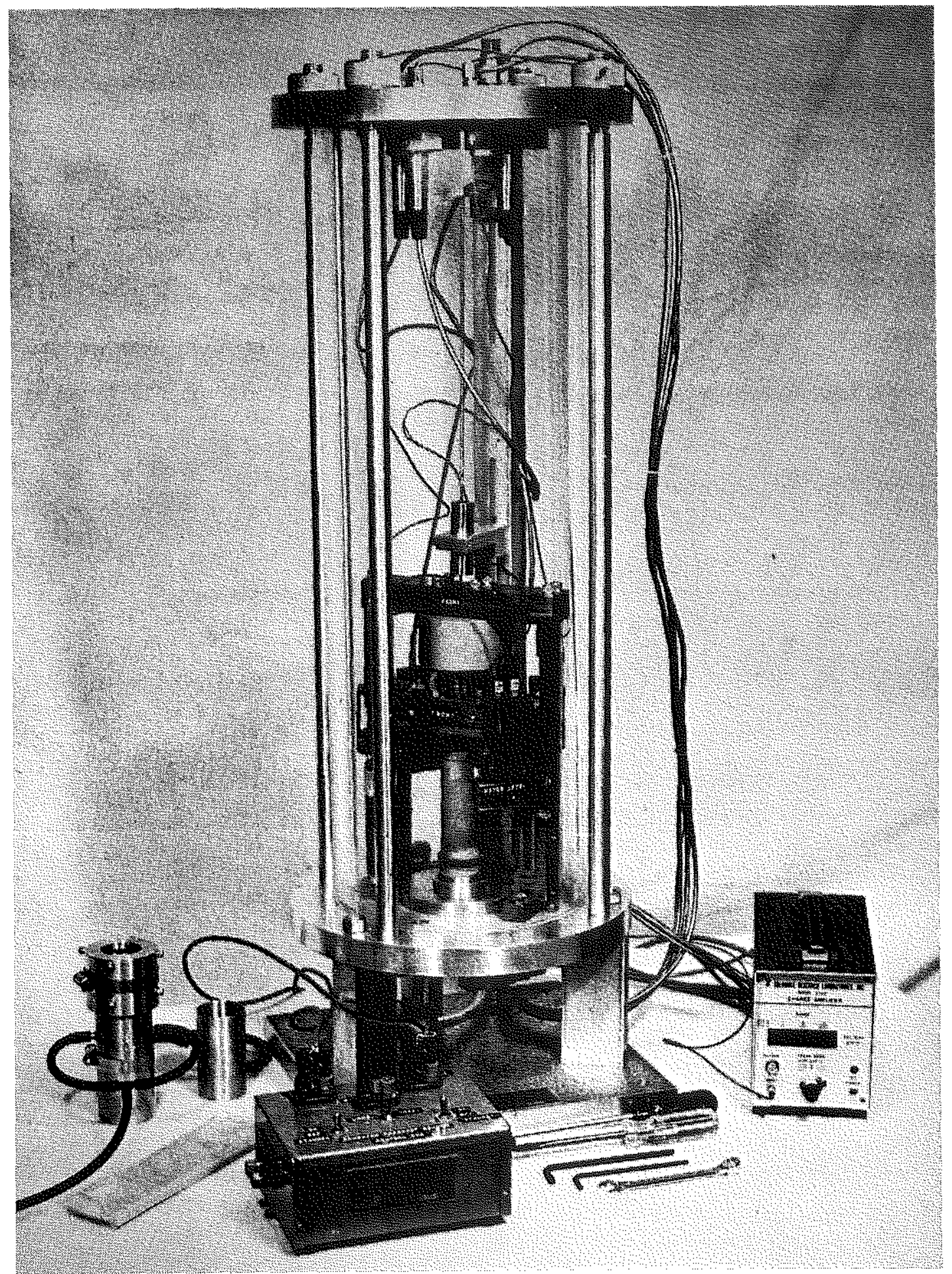

Figure 1. The Drnevich Longitudinal-torsional Resonant column, without Electronics. 


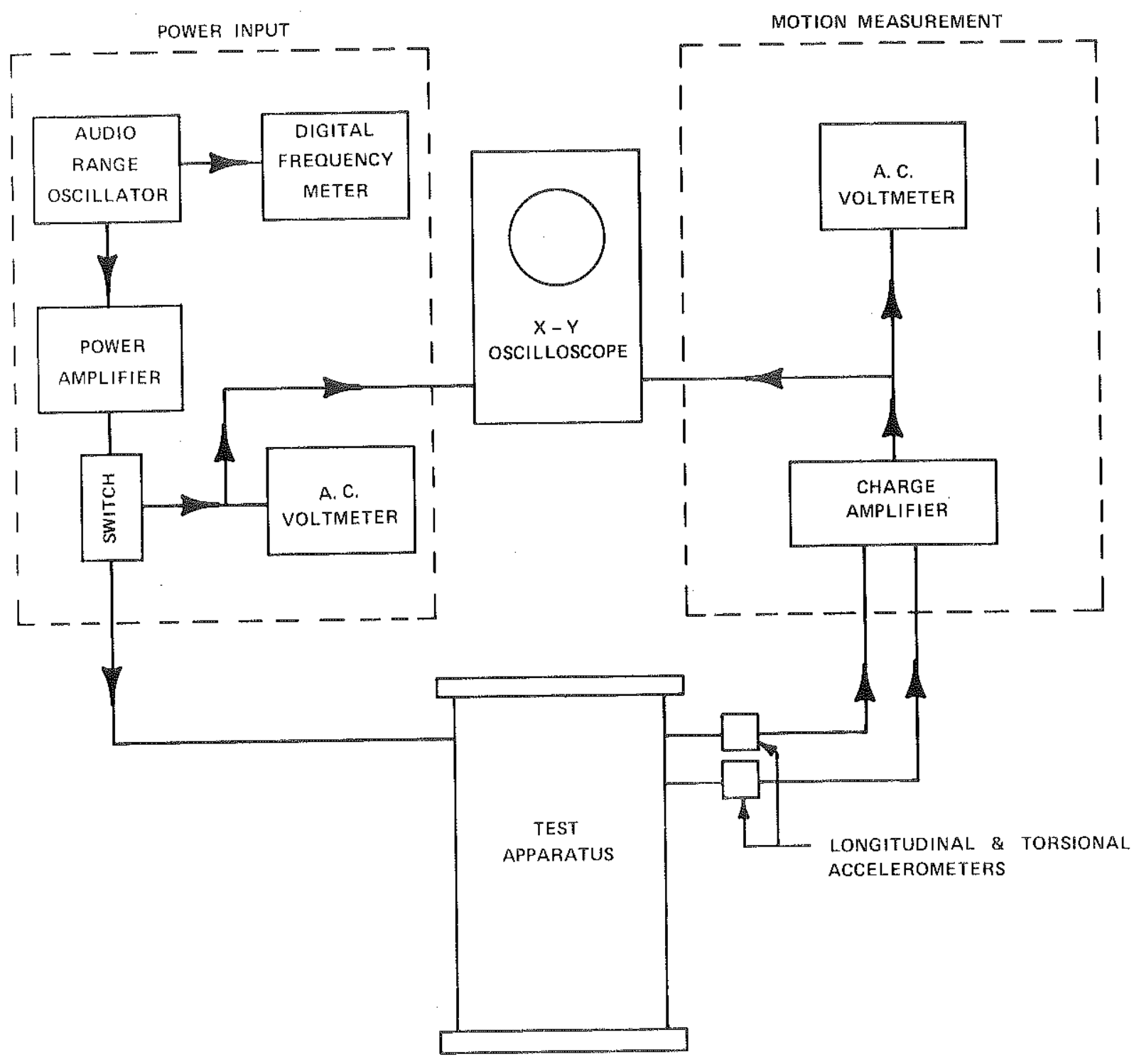

Figure 2. Schematic Diagram of the Electronics for the Resonant Column. 


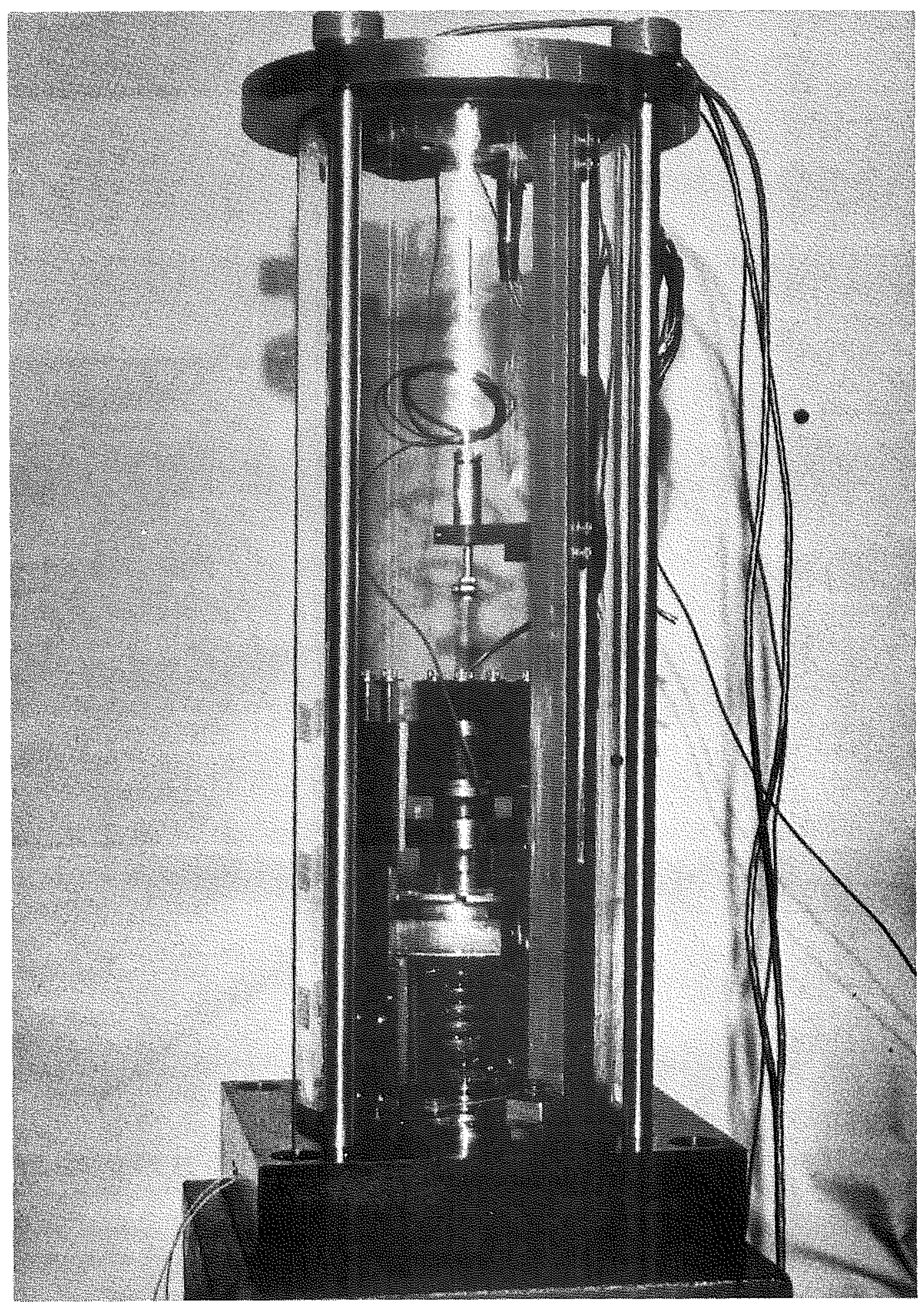

Figure 3. The Drnevich Longitudinal-Torsional Resonant Column, without Electronics, as Modified for this Study. 


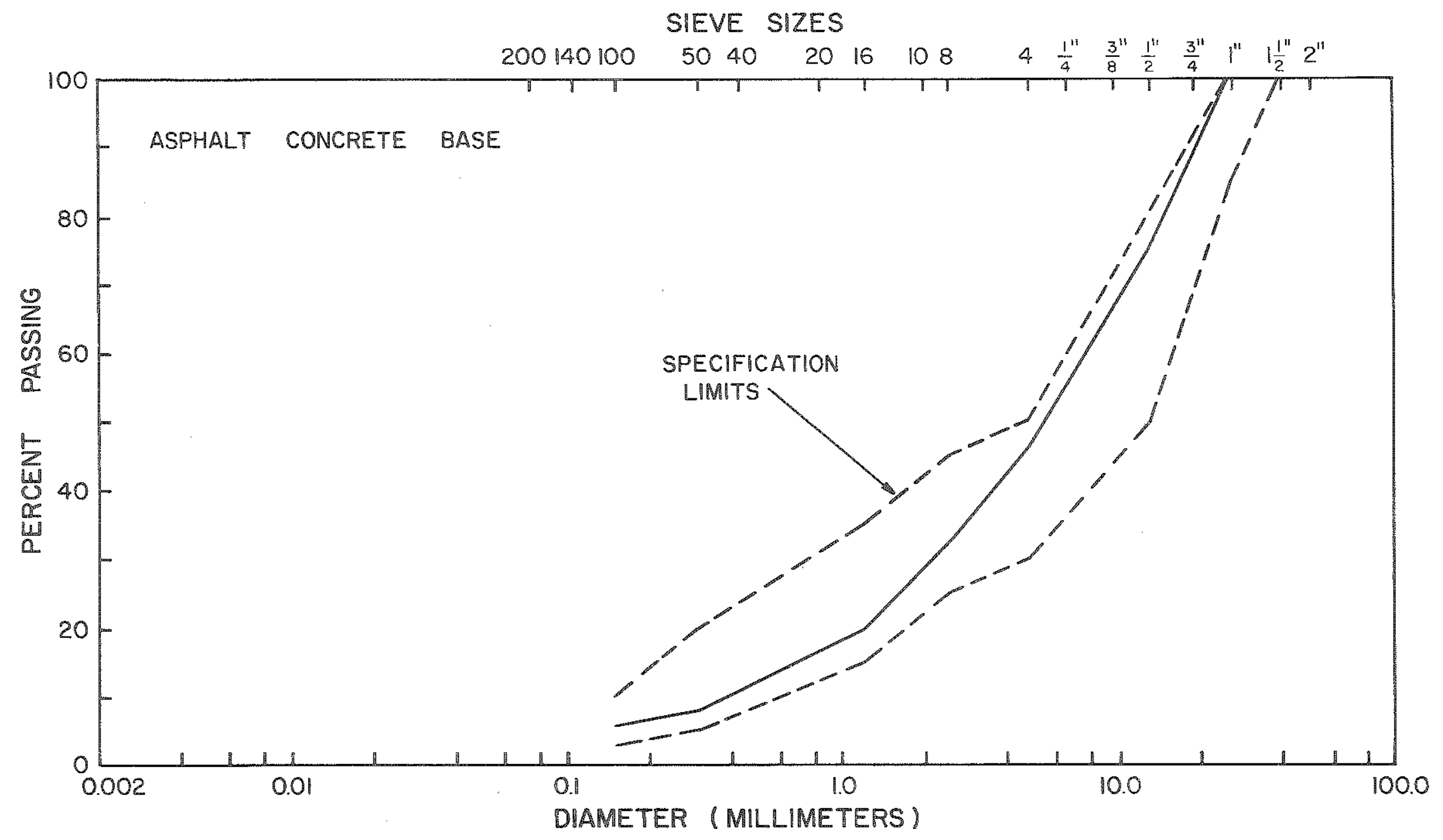

Figure 4. Gradation of the Asphaitic Concrete Base. 


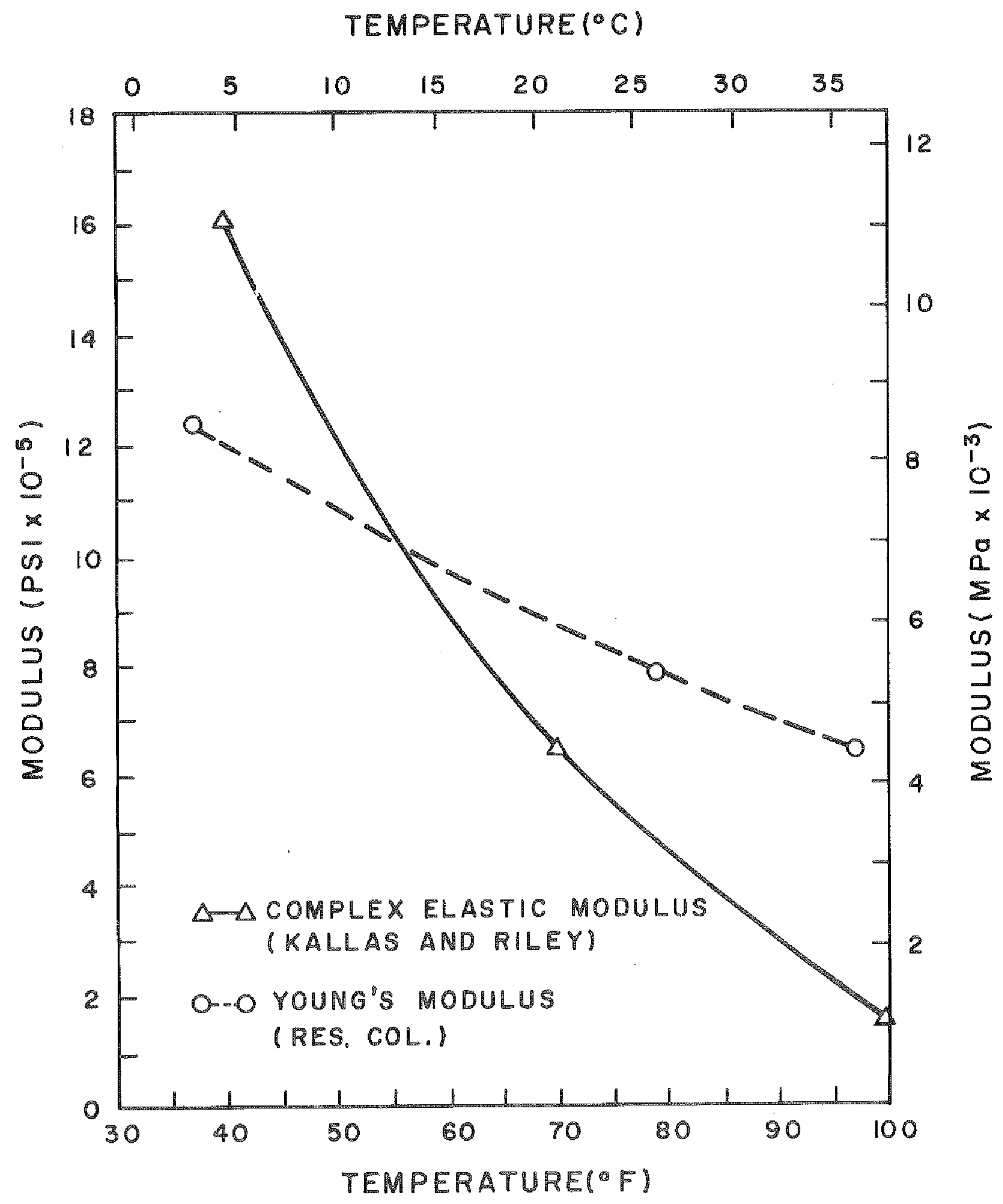

Figure 5. Relationship between Modulus and Temperature. 


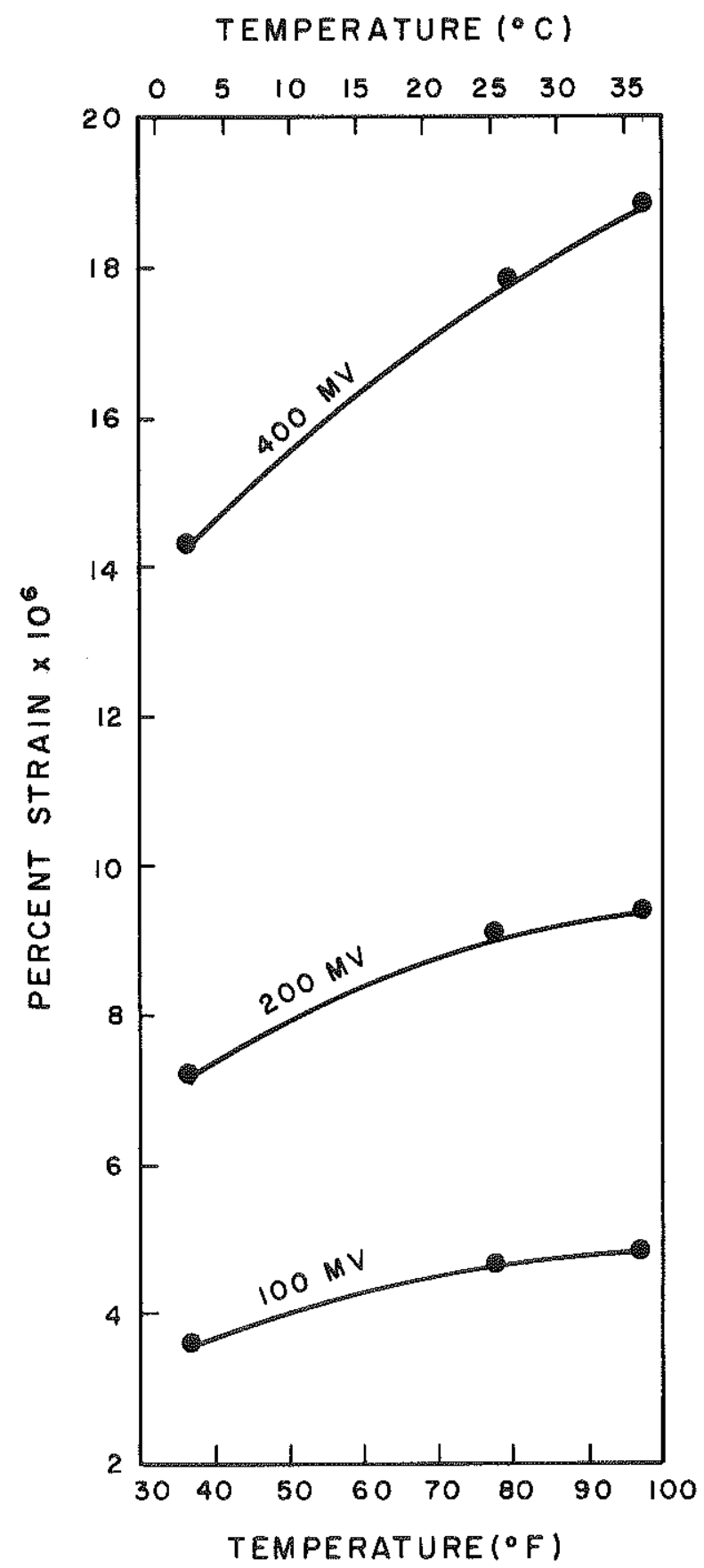

Figure 6. Effects of Temperature and Force Magnitude on Strain Amplitude. 


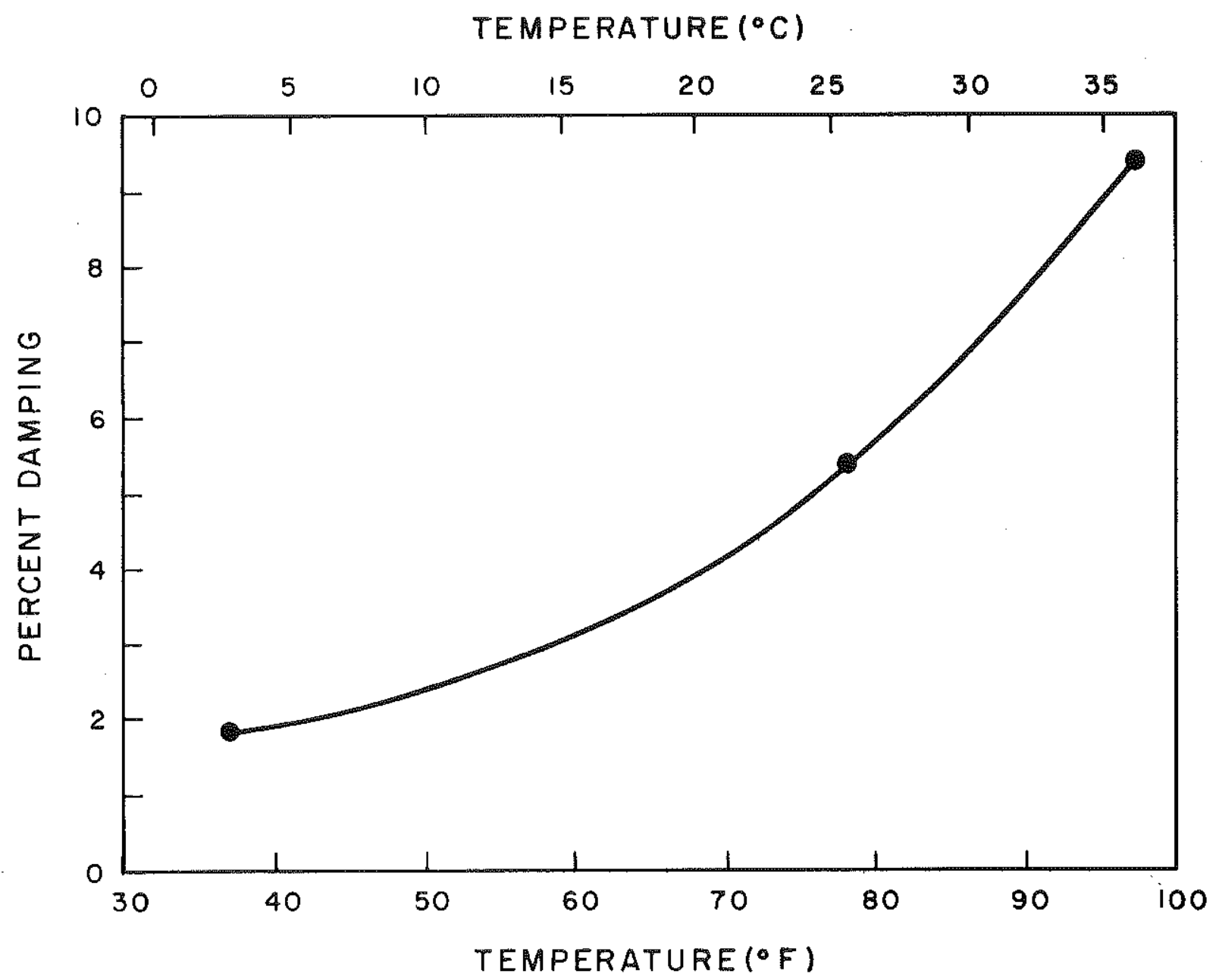

Figure 7. Relationship between Percent Damping and Temperature. 
